\title{
Synthesis, Spectral Characterization, and Antibacterial and Antifungal Studies of PANI/ $\mathbf{V}_{2} \mathbf{O}_{5}$ Nanocomposites
}

\author{
Chakradhar Sridhar B, ${ }^{1}$ Nagesh Gunvanthrao Yernale, ${ }^{2}$ and M. V. N. Ambika Prasad ${ }^{1}$ \\ ${ }^{1}$ Department of Studies and Research in Physics, Gulbarga University, Kalaburagi, Karnataka 585 106, India \\ ${ }^{2}$ Department of Studies and Research in Chemistry, Gulbarga University, Kalaburagi, Karnataka 585 106, India \\ Correspondence should be addressed to Chakradhar Sridhar B; chakradhar.rcr@gmail.com
}

Received 1 December 2015; Revised 16 March 2016; Accepted 20 March 2016

Academic Editor: Jose C. Merchuk

Copyright ( 2016 Chakradhar Sridhar B et al. This is an open access article distributed under the Creative Commons Attribution License, which permits unrestricted use, distribution, and reproduction in any medium, provided the original work is properly cited.

\begin{abstract}
The present study deals with the synthesis and characterization of nanocrystalline vanadium pentoxide $\left(\mathrm{V}_{2} \mathrm{O}_{5}\right)$ nanoparticles and their antibacterial and antifungal activity on Staphylococcus aureus and Aspergillus niger, respectively, by agar diffusion method. The metal oxide has been synthesized by employing the sol-gel method, polyaniline (PANI) has been synthesized by chemical oxidation, and PANI $/ \mathrm{V}_{2} \mathrm{O}_{5}$ composites have been synthesized by in situ polymerization method with different ratios $(10,20,30,40$, and 50 weight\%) of $\mathrm{V}_{2} \mathrm{O}_{5}$ in PANI. The newly prepared composites were characterized by FTIR and powder X-ray diffraction (P-XRD) techniques and are found to be formed of PANI/ $\mathrm{V}_{2} \mathrm{O}_{5}$ nanocomposites, and also the compounds showed moderate antibacterial and antifungal activity.
\end{abstract}

\section{Introduction}

Conducting polymers are unique because they show electrical, biological, and optical property changes when they are chemically treated with oxidizing or reducing agents. After chemical treatment with redox active agents, these polymers can change from an initial insulating state to an electrically conducting state [1]. This transition can be used in such applications as chemical sensors [2,3], optical sensors [4], and biosensors $[5,6]$. The most widely studied conducting polymers include polyaniline, polypyrrole, and polythiophene. Polyaniline is appealing because it is environmentally stable, is easily synthesized, and can react with chemical species at room temperature [7]. The nanoparticles composites materials have unique physical properties that have attracted more and more attention as a cathode in rechargeable ion batteries and selective gas sensors such as ammonia because of their high surface area and redox activity $[8,9]$. Biological activity of vanadium pentoxide nanomaterial depends on factors such as the type of the derivative, manner of its administration, dose, length of treatment, and also individual- and speciesspecific sensitivity to the administered compound [10]. $\mathrm{V}_{2} \mathrm{O}_{5}$ nanomaterial is amphoteric in nature. Vanadium is correlated to its degree of oxidation (vanadyl $\mid$ vanadate ion) and chemical form (organic|inorganic ligand) [11-13]. The existence of the various vanadate species depends on the $\mathrm{pH}$ and on the total concentration of vanadium. Their occurrence can be accounted for by protonation and condensation equilibrium; it is evident that only in very dilute solutions are monomeric vanadium ions found, and increases in concentration, particularly if the solution is acidic, lead to polymerization [14-16].

In the recent past, the conducting polymer-based nanocomposites have drawn attention to their application as potent biological agents [17-21]. Therefore, $\mathrm{PANI}-\mathrm{V}_{2} \mathrm{O}_{5} \mathrm{com}$ posites have been most intensively studied among various composites, because they could combine the merits of PANI and crystalline $\mathrm{V}_{2} \mathrm{O}_{5}$ within a single material and are expected to have applications in potent biological agents.

\section{Experimental}

2.1. Materials and Methods. The monomer aniline was distilled twice before use; an AR grade ammonium persulfate $\left[\left(\mathrm{NH}_{4}\right)_{2} \mathrm{~S}_{2} \mathrm{O}_{8}\right]$, hydrochloric acid $(\mathrm{HCl})$, and vanadium pentoxide $\left(\mathrm{V}_{2} \mathrm{O}_{5}\right)$ were used for synthesis. 
2.2. Synthesis of $\mathrm{V}_{2} \mathrm{O}_{5}$ Nanoparticles. The sol solution of vanadium nitrate hydrate and citric acid in double distilled water with specific weight percentages was prepared. The resulting mixture was dissolved by constant stirring for about $24 \mathrm{~h}$ at $40^{\circ} \mathrm{C}$ until a clear solution was obtained and was refluxed for about $1 \mathrm{~h}$. During the reflux, the solution turns into a metal-citrate homogeneous complex with a slight color change from milky white to a clear solution. The completion of the reaction gives rise to the formation of the complex and the evaporation of the solvent forms a gel. Further, the gel was kept in hot air oven by slow heating up to $100^{\circ} \mathrm{C}$ for $3 \mathrm{~h}$; there will be chelation between metal ions and citric acid [22]. This process helps in achieving a proper stoichiometry and control of the particle size without any need of a special atmosphere and also improves uniformity of the distribution of the metal ions in the solution. In the final step of the sol-gel process, the wet gel was fully dried by direct heating on the hot plate at $180-200^{\circ} \mathrm{C}$ for $5 \mathrm{~h}$. The resulting white powder $\left(\mathrm{V}_{2} \mathrm{O}_{5}\right)$ was obtained.

The PANI $/ \mathrm{V}_{2} \mathrm{O}_{5}$ composites were prepared by in situ polymerization method. To the mixture of double distilled aniline $(0.1 \mathrm{~mol})$ and hydrochloric acid $(1 \mathrm{M}), \mathrm{V}_{2} \mathrm{O}_{5}$ was added in five different weights $(10,20,30,40$, and 50 weight\%) with vigorous stirring to keep $\mathrm{V}_{2} \mathrm{O}_{5}$ suspended in the solution. $11.2 \mathrm{~g}$ of ammonium persulfate was added slowly with constant stirring at $0-5^{\circ} \mathrm{C}$. The reaction mixture was kept for stirring for about $24 \mathrm{~h}$. The greenish precipitate was formed which was recovered by vacuum filtration and washed several times with distilled water. The obtained composite PANI/ $\mathrm{V}_{2} \mathrm{O}_{5}$ is kept in oven for drying for $24 \mathrm{~h}$ to get a constant weight [23].

2.3. Antibacterial and Antifungal Activity. The antibacterial and antifungal activity of PANI, $\mathrm{V}_{2} \mathrm{O}_{5}$, and PANI/ $\mathrm{V}_{2} \mathrm{O}_{5}$ nanocomposites were performed by the agar diffusion method $[24,25]$. The antibacterial activity of the test compounds is tested against Gram-positive bacteria, Staphylococcus aureus (MTCC 3160), and antifungal activity against Aspergillus niger (MTCC 1881) in accordance with the international recommendation provided by the Clinical and Laboratory Standard Institute (CLSI). The above organisms were obtained from the Department of Microbiology and Biotechnology, Gulbarga University, Kalaburagi, Karnataka, India, which are previously procured from Institute of Microbial Technology Chandigarh, India. The stock solutions of each test compound $\left(1 \mathrm{mg} \mathrm{mL}^{-1}\right)$ were prepared by dissolving $10 \mathrm{mg}$ of the each test compound in $10 \mathrm{~mL}$ of freshly distilled DMSO. Further, the various concentrations of the test compounds $(25,50,100,250,500$, and $1000 \mu \mathrm{g})$ were prepared by diluting the stock solutions with the required volume of freshly distilled DMSO.

2.3.1. Antibacterial Activity. The media were prepared by dissolving peptone $10 \mathrm{~g}, \mathrm{NaCl} 10 \mathrm{~g}$, yeast extract $5 \mathrm{~g}$, and agar $20 \mathrm{~g}$ in $1000 \mathrm{~mL}$ of distilled water. Initially, the stock cultures of bacteria were revived by inoculating in broth media and grown at $37^{\circ} \mathrm{C}$ for $18 \mathrm{~h}$. The agar plates were prepared and wells were made in the plate. Further, each plate was inoculated with $18 \mathrm{~h}$ old cultures $\left(100 \mu \mathrm{L}, 10^{-4} \mathrm{cfu}\right)$ and spread evenly on the plate. After $20 \mathrm{~min}$, the wells were filled with newly prepared compounds and standard antibiotic, Ciprofloxacin, at different concentrations $(25,50,100,250$, 500 , and $1000 \mu \mathrm{g})$. All the plates were incubated at $37^{\circ} \mathrm{C}$ for $24 \mathrm{~h}$ and the diameter of inhibition zone was measured. The experiment was done in triplicate and the average values were calculated for antibacterial activity.

2.3.2. Antifungal Activity. The media were prepared by using Czapek-Dox Agar (composition (g/L): sucrose 30.0; sodium nitrate 2.0; $\mathrm{K}_{2} \mathrm{HPO}_{4} 1.0, \mathrm{MgSO}_{4} .7 \mathrm{H}_{2} \mathrm{O} 0.5 ; \mathrm{KCl} 0.5 ; \mathrm{FeSO}_{4}$ 0.01 ; agar 20). Initially, the stock cultures were revived by inoculating in broth media and grown at $27^{\circ} \mathrm{C}$ for $48 \mathrm{~h}$. The agar plates of the above media were prepared and wells were made in the plate. Each plate was inoculated with $48 \mathrm{~h}$ old cultures ( $\left.100 \mu \mathrm{L} 10^{4} \mathrm{CFU}\right)$ and spread evenly on the plate. After $20 \mathrm{~min}$, the wells were filled with different concentrations $(25,50,100,250,500$, and $1000 \mu \mathrm{g})$ of samples and antibiotic, Fluconazole. All the plates were incubated at $27^{\circ} \mathrm{C}$ for $96 \mathrm{~h}$ and the diameter of inhibition zone was noted. The experiment was done in triplicate and the average values were calculated for antibacterial activity.

The minimum concentration of each test compound with no visible growth of test bacteria/fungi was reported as MIC for their respective strains. Blank tests have shown that DMSO in the preparation of the test solution does not affect the test organisms.

2.4. Physical Measurement. The FTIR spectra were recorded on a Perkin Elmer 1600 spectrophotometer in $\mathrm{KBr}$ and powder X-ray diffraction studies were performed by Philips $\mathrm{X}$-ray diffractometer with $\mathrm{Cu} \mathrm{K} \alpha$ as a radiation source.

\section{Results and Discussions}

3.1. FTIR Spectral Data. The prominent peak (Figure 1(a)) observed at $2924 \mathrm{~cm}^{-1}$ is due to $\mathrm{CH}_{2}$ asymmetric stretching, peak at $1603 \mathrm{~cm}^{-1}$ confirms the formation of PANI, and peaks at $1574 \mathrm{~cm}^{-1}$ and $1494 \mathrm{~cm}^{-1}$ may be attributed to the presence of quinoid $(\mathrm{N}=\mathrm{Q}=\mathrm{N})$ and benzenoid $(\mathrm{N}=\mathrm{B}=\mathrm{N})$ ring stretching. Also, the peaks observed at $1303 \mathrm{~cm}^{-1}, 1146 \mathrm{~cm}^{-1}$, $734 \mathrm{~cm}^{-1}$, and $502 \mathrm{~cm}^{-1}$ are due to N-H deformation, C-O-C stretching of excess oxidant, and $\mathrm{C}-\mathrm{H}$ vibration of $\mathrm{p}$-coupling benzenoid ring and aromatic ring, respectively [26].

The FTIR spectrum of $\mathrm{V}_{2} \mathrm{O}_{5}$ nanoparticles (Figure $1(\mathrm{~b})$ ) shows absorption bands at $1022 \mathrm{~cm}^{-1}$, and $817 \mathrm{~cm}^{-1}$ and $580 \mathrm{~cm}^{-1}$ are assigned to $\mathrm{V}=\mathrm{O}$ stretching band and $\mathrm{V}-\mathrm{O}-\mathrm{V}$ deformation modes, respectively [27].

Also, the FTIR spectrum (Figure 1(c)) of mixture of $\mathrm{PANI} / \mathrm{V}_{2} \mathrm{O}_{5}$ nanoparticles with 50 weight $\%$ displayed the absorption bands at $3431 \mathrm{~cm}^{-1}, 2920 \mathrm{~cm}^{-1}, 1600 \mathrm{~cm}^{-1}, 1572 \mathrm{~cm}^{-1}$, $1492 \mathrm{~cm}^{-1}, 1301 \mathrm{~cm}^{-1}, 1145 \mathrm{~cm}^{-1}, 1020 \mathrm{~cm}^{-1}, 810 \mathrm{~cm}^{-1}$, and $578 \mathrm{~cm}^{-1}$, confirming the presence of $\mathrm{V}_{2} \mathrm{O}_{5}$ in PANI. When comparing the FTIR spectra of PANI and $\mathrm{V}_{2} \mathrm{O}_{5}$ nanoparticles (Figures 1(a) and 1(b)), it is clearly observed that some of the absorption frequencies are slightly shifted towards lower side, 


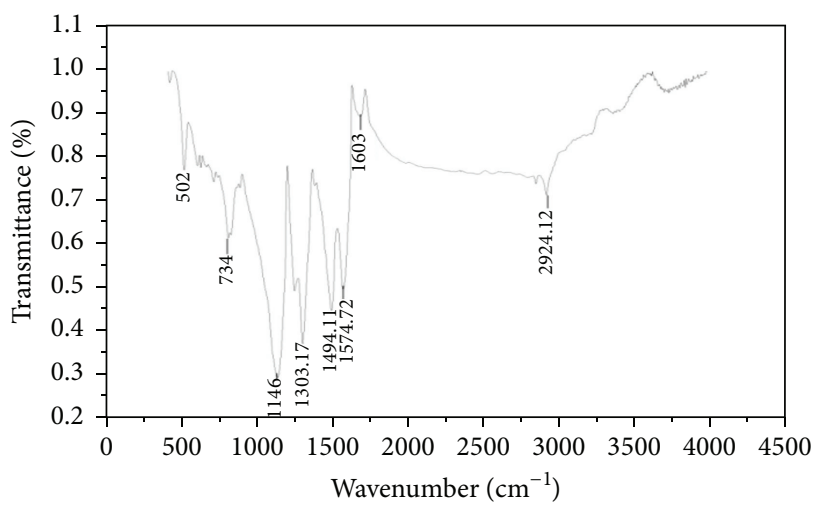

(a) Pure PANI

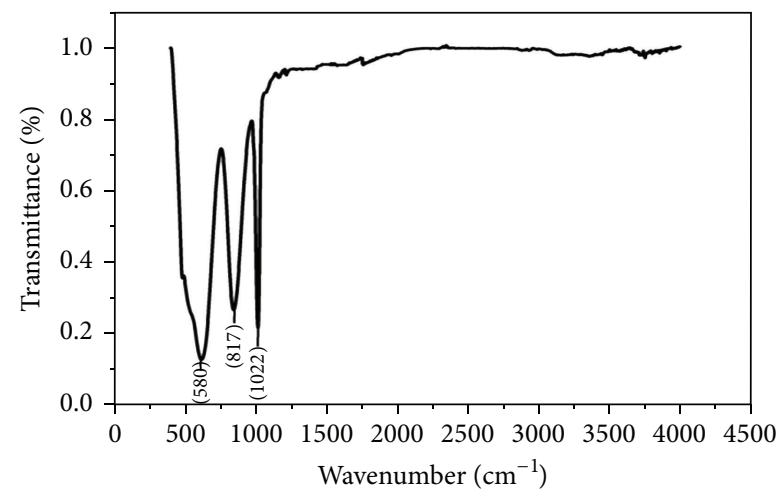

(b) Pure $\mathrm{V}_{2} \mathrm{O}_{5}$

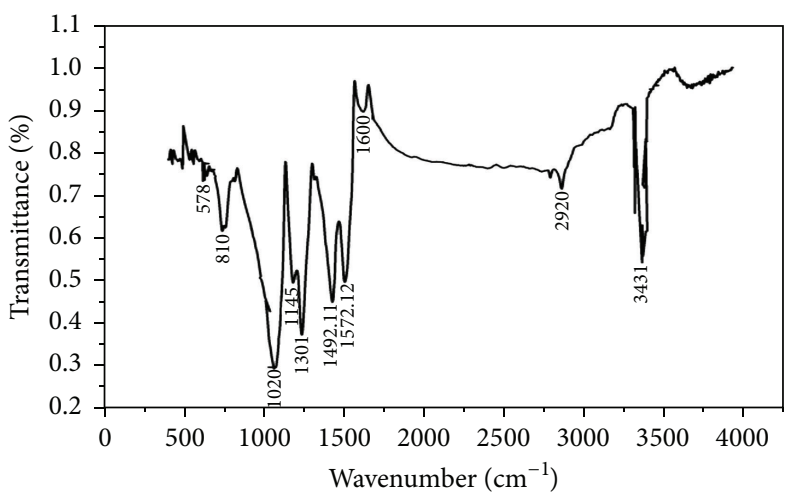

(c) $\mathrm{V}_{2} \mathrm{O}_{5} 50 \mathrm{wt} \%$ in PANI

FIgURE 1: (a) FTIR spectrum of PANI. (b) FTIR spectrum of $\mathrm{V}_{2} \mathrm{O}_{5}$ nanoparticle. (c) FTIR spectrum of 50 weight\% of $\mathrm{V}_{2} \mathrm{O}_{5}$ in PANI $\left(\mathrm{V}_{2} \mathrm{O}_{5}\right.$ /PANI nanocomposite).

which is due to the weak Vander Waals force and confirms the formation of nanocomposite.

3.2. Powder X-Ray Diffraction. The powder X-ray analysis data (Figure 2(a)) shows the amorphous nature of the PANI with the appearance of a broad peak centered at $2 \theta \approx 25.53^{\circ}$, which corresponds to $h k l$ values of $(200)$ diffraction planes PANI [28].

The powder X-ray diffraction pattern of $\mathrm{V}_{2} \mathrm{O}_{5}$ nanoparticle (Figure 2(b)) shows thegood crystallinity nature. The formations of nanoparticles are confirmed by the existence of sharp peaks. The crystallite size of the synthesized $\mathrm{V}_{2} \mathrm{O}_{5}$ nanoparticle was calculated using Scherer's formula: $D=$ $0.9 \lambda / \beta \cos \theta$.

The average crystallite size of $\mathrm{V}_{2} \mathrm{O}_{5}$ nanoparticles is found to be $\sim 11 \mathrm{~nm}$. In the XRD spectra (Figure 2(b)), it was observed that the different peaks are attributed to the $h k l$ values of (2 00$),(001),(110),(400),(011),(310),(002),(411)$, (6 00$),(601),(121),(420)$, and (710) planes which are in good agreement with the data of $\mathrm{V}_{2} \mathrm{O}_{5}$ powder file (JCPDS number 09-0387) which corresponds to the orthorhombic crystalline structure. The XRD spectrum exhibits an intense $\left(\begin{array}{lll}0 & 0 & 1\end{array}\right)$ peak indicating preferential orientation in the $\langle 001\rangle$ direction. This result reveals that the structure is such that the crystallographic $c$-axis is perpendicular to the substrate surface and the crystalline orientation is favored [29].

In the powder X-ray diffraction pattern (Figure 2(c)) of PANI/ $\mathrm{V}_{2} \mathrm{O}_{5}$ nanocomposite with 50 weight $\%$ of $\mathrm{V}_{2} \mathrm{O}_{5}$ nanoparticles in PANI, the various sharp peaks are attributed to the $h \mathrm{kl}$ values of (200), (001), (110), (400), (011), (310), (0 02 ), and (310) planes. In comparison (Figures 2(a) and 2(b)), it is clearly revealed that $\mathrm{V}_{2} \mathrm{O}_{5}$ nanoparticle has retained its structure even though it is dispersed in PANI during the process of polymerization.

3.3. Antibacterial and Antifungal Activity Results. The antibacterial and antifungal activities of newly prepared compounds were examined for their effect on $S$. aureus and $A$. niger, respectively, by minimum inhibitory concentration (MIC) method. The minimum concentration of each test compound with no visible growth of test bacteria/fungi was reported as MIC for their respective strains [30, 31]. The compound $\mathrm{V}_{2} \mathrm{O}_{5}$ and $\mathrm{PANI} / \mathrm{V}_{2} \mathrm{O}_{5}$ showed the moderate antibacterial activity at $100 \mu \mathrm{g}$ concentration. Further, the compound $\mathrm{V}_{2} \mathrm{O}_{5}$ showed moderate antifungal activity at $50 \mu \mathrm{g}$ concentration. The obtained results were compared 


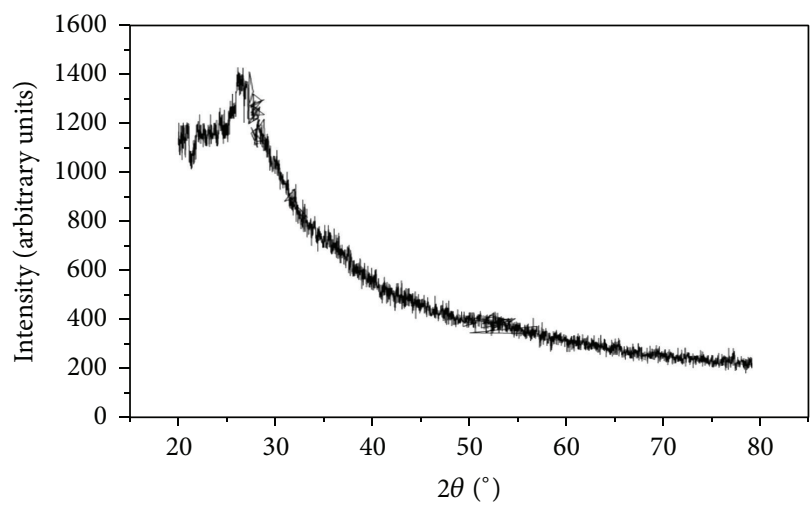

(a) Pure PANI

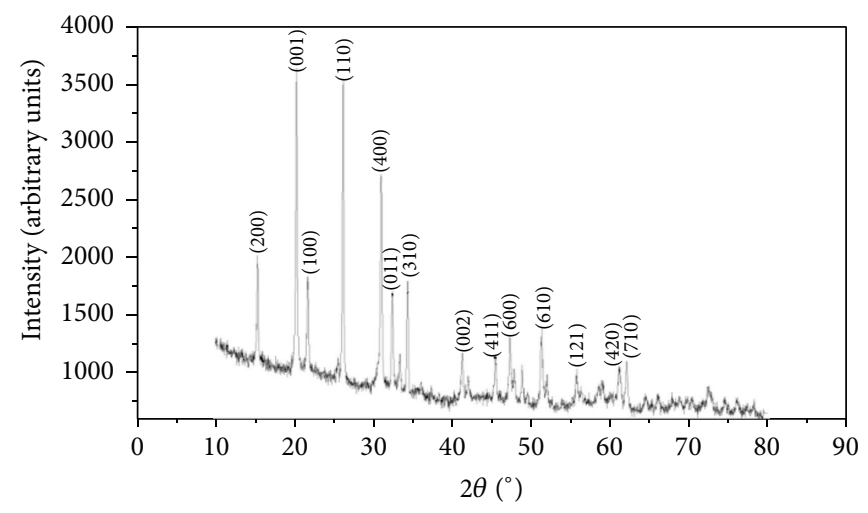

(b) Pure $\mathrm{V}_{2} \mathrm{O}_{5}$

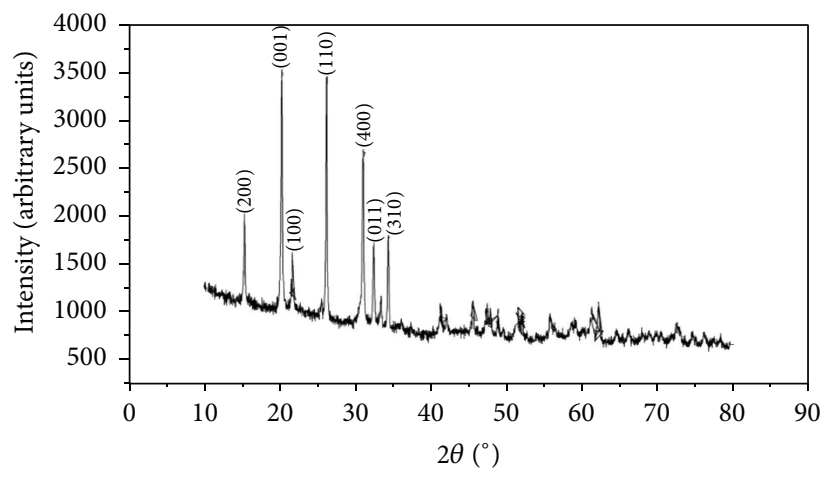

(c) $50 \mathrm{wt} \%$ of $\mathrm{V}_{2} \mathrm{O}_{5}$ in PANI

Figure 2: (a) Powder X-ray diffraction pattern of PANI. (b) Powder X-ray diffraction pattern of $\mathrm{V}_{2} \mathrm{O}_{5}$ nanoparticle. (c) Powder X-ray diffraction pattern of 50 weight $\%$ of $\mathrm{V}_{2} \mathrm{O}_{5}$ in PANI $\left(\mathrm{V}_{2} \mathrm{O}_{5} /\right.$ PANI nanocomposite).

TABLE 1: Antibacterial activity results, zone of inhibition in $\mathrm{mm}$ (S. aureus).

\begin{tabular}{lccccccc}
\hline Samples & $25 \mu \mathrm{g}$ & $50 \mu \mathrm{g}$ & $100 \mu \mathrm{g}$ & $250 \mu \mathrm{g}$ & $500 \mu \mathrm{g}$ & $1000 \mu \mathrm{g}$ & $\mathrm{MIC} \mu \mathrm{g}$ \\
\hline PANI & 0 & 0 & 0 & 7 & 8 & 12 & 15 \\
$\mathrm{~V}_{2} \mathrm{O}_{5}$ & 0 & 0 & 9 & 11 & 15 & 19 & 100 \\
PANI $/ \mathrm{V}_{2} \mathrm{O}_{5}$ & 0 & 0 & $*$ & $*$ & $*$ & 22 & 100 \\
Ciproflaxacin & $*$ & $*$ & & & $*$ & $*$ \\
\hline
\end{tabular}

${ }^{*}$ Inhibitions zones were too big to measure.

TABLE 2: Antifungal activity results, zone of inhibition in $\mathrm{mm}$ (A. niger).

\begin{tabular}{|c|c|c|c|c|c|c|c|}
\hline Sample & $25 \mu \mathrm{g}$ & $50 \mu \mathrm{g}$ & $100 \mu \mathrm{g}$ & $250 \mu \mathrm{g}$ & $500 \mu \mathrm{g}$ & $1000 \mu \mathrm{g}$ & MIC $\mu \mathrm{g}$ \\
\hline$\frac{1}{\text { PANI }}$ & 0 & 0 & 0 & 6 & 10 & 19 & 250 \\
\hline $\mathrm{V}_{2} \mathrm{O}_{5}$ & 0 & 7 & 13 & 19 & 22 & 20 & 50 \\
\hline $\mathrm{PANI} / \mathrm{V}_{2} \mathrm{O}_{5}$ & 0 & 0 & 5 & 9 & 14 & 21 & 100 \\
\hline Fluconazole & 5 & 14 & 22 & $*$ & $*$ & $*$ & 25 \\
\hline
\end{tabular}

${ }^{*}$ Inhibitions zones were too big to measure.

with that of Ciprofloxacin, a broad-spectrum antibiotic for bacterial strains, and Fluconazole for fungal strains as positive control and results are presented in Tables 1 and 2 respectively.

\section{Conclusions}

The PANI and $\mathrm{V}_{2} \mathrm{O}_{5}$ nanoparticles and PANI/ $\mathrm{V}_{2} \mathrm{O}_{5}$ nanocomposites have been successfully synthesized by chemical oxidation, sol-gel, and in situ polymerization methods, respectively. The prepared samples were well characterized and their formation was confirmed by FTIR and powder Xray diffraction techniques. These data suggest the formation of composites. Further, the prepared compounds behaved as antibacterial and antifungal agents. Hence, from all these extensive observations, it was concluded that the prepared compounds give the remarkable, versatile, and valuable information to materials chemistry and also they may be used as good biological agents with reduced toxicity and higher efficiency. 


\section{Competing Interests}

The authors declare that there are no competing interests regarding the publication of this paper.

\section{Acknowledgments}

One of the authors acknowledges the support extended by the Department of Science and Technologies (DST) in carrying out this work (DST Project Sanction Letter no. ST/TSG/PT/2009/133). Authors are also thankful for BioGenics Research and Training Centre in Biotechnology, Hubli, for biological studies.

\section{References}

[1] R. S. Kohlman and A. J. Epstein, Handbook of Conducting Polymers, Marcel Dekker, New York, NY, USA, 2nd edition, 1998.

[2] A. Bossi, S. A. Piletsky, E. V. Piletska, P. G. Righetti, and A. P. F. Turner, "An assay for ascorbic acid based on polyaniline-coated microplates," Analytical Chemistry, vol. 72, no. 18, pp. 42964300, 2000 .

[3] J. Janata and M. Josowicz, "Conducting polymers in electronic chemical sensors," Nature Materials, vol. 2, no. 1, pp. 19-24, 2003.

[4] E. Pringsheim, D. Zimin, and O. S. Wolfbeis, "Floorescent beads coated with polyaniline: a novel nanomaterial for optical sensing of pH," Advanced Materials, vol. 13, pp. 819-822, 2001.

[5] M. Gao, L. Dai, and G. G. Wallace, "Biosensors based on aligned carbon nanotubes coated with inherently conducting polymers," Electroanalysis, vol. 15, no. 13, pp. 1089-1094, 2003.

[6] S. Sukeerthi and A. Q. Contractor, "Molecular sensors and sensor arrays based on polyaniline microtubules," Analytical Chemistry, vol. 71, no. 11, pp. 2231-2236, 1999.

[7] W.-S. Huang, B. D. Humphrey, and A. G. MacDiarmid, "Polyaniline, a novel conducting polymer. Morphology and chemistry of its oxidation and reduction in aqueous electrolytes," Journal of the Chemical Society, Faraday Transactions 1: Physical Chemistry in Condensed Phases, vol. 82, no. 8, pp. 23852400, 1986.

[8] R. Sahay, P. S. Kumar, R. Sridhar et al., "Electrospun composite nanofibers and their multifaceted applications," Journal of Materials Chemistry, vol. 22, no. 26, pp. 12953-12971, 2012.

[9] M. Sethupathy, S. Ravichandran, and P. Manisankar, "Preparation of PVdF-PAN- $\mathrm{V}_{2} \mathrm{O}_{5}$ hybrid composite membrane by electrospinning and fabrication of dye-sensitized solar cells," International Journal of Electrochemical Science, vol. 9, pp. 31663180, 2014.

[10] P. Gill, T. T. Moghadam, and B. Ranjbar, "Differential scanning calorimetry techniques: applications in biology and nanoscience," Journal of Biomolecular Techniques, vol. 21, no. 4, pp. 167-193, 2010.

[11] J. Livage, "Hydrothermal synthesis of nanostructured vanadium oxides," Materials, vol. 3, no. 8, pp. 4175-4195, 2010.

[12] G. Y. Nagesh, K. M. Raj, and B. H. M. Mruthyunjayaswamy, "Synthesis, characterization, thermal study and biological evaluation of $\mathrm{Cu}(\mathrm{II}), \mathrm{Co}(\mathrm{II}), \mathrm{Ni}(\mathrm{II})$ and $\mathrm{Zn}$ (II) complexes of Schiff base ligand containing thiazole moiety," Journal of Molecular Structure, vol. 1079, pp. 423-432, 2015.
[13] G. Y. Nagesh and B. H. M. Mruthyunjayaswamy, "Synthesis, characterization and biological relevance of some metal (II) complexes with oxygen, nitrogen and oxygen (ONO) donor Schiff base ligand derived from thiazole and 2-hydroxy-1naphthaldehyde," Journal of Molecular Structure, vol. 1085, pp. 198-206, 2015.

[14] A. M. Evangelou, "Vanadium in cancer treatment," Critical Reviews in Oncology/Hematology, vol. 42, no. 3, pp. 249-265, 2002.

[15] J. L. Domingo, "Vanadium and tungsten derivatives as antidiabetic agents: a review of their toxic effects," Biological Trace Element Research, vol. 88, no. 2, pp. 97-112, 2002.

[16] N. N. Greenwood and A. Earnshaw, Chemistry of the Elements, Pergamon Press, Oxford, UK, 1st edition, 1989.

[17] M. M. Pérez-Madrigal, E. Armelin, J. Puiggalí, and C. Alemán, "Insulating and semiconducting polymeric freestanding nanomembranes with biomedical applications," Journal of Materials Chemistry B, vol. 3, no. 29, pp. 5904-5932, 2015.

[18] U. K. Sur, "Graphene: a rising star on the horizon of materials science," International Journal of Electrochemistry, vol. 2012, Article ID 237689, 12 pages, 2012.

[19] S. Lupu, "New developments in electrochemical sensors based on poly(3,4-ethylenedioxythiophene)-modified electrodes," International Journal of Electrochemistry, vol. 2011, Article ID 508126, 8 pages, 2011.

[20] B. H. M. Mruthyunjayaswamy, G. Y. Nagesh, M. Ramesh, B. Priyanka, and B. Heena, "Synthesis, characterization and antioxidant activity of Schiff base ligand and its metal complexes containing thiazole moiety," Der Pharma Chemica, vol. 7, no. 10, pp. 556-562, 2015.

[21] K. Mahendra Raj, B. Vivekanand, G. Y. Nagesh, and B. H. M. Mruthyunjayaswamy, "Synthesis, spectroscopic characterization, electrochemistry and biological evaluation of some binuclear transition metal complexes of bicompartmental ONO donor ligands containing benzo[b] thiophene moiety," Journal of Molecular Structure, vol. 1059, no. 1, pp. 280-293, 2014.

[22] Ch. V. S. Reddy, P. Kyung-Il, M. Sun-il, Y. In-Hyeong, and P. SuMoon, "Simple preparation of $\mathrm{V}_{2} \mathrm{O}_{5}$ nanostructures and their characterization," Bulletin of the Korean Chemical Society, vol. 29, no. 10, pp. 2061-2064, 2008.

[23] G. Li, C. Zhang, H. Peng, and K. Chen, "One-dimensional $\mathrm{V}_{2} \mathrm{O}_{5} @$ polyaniline core/shell nanobelts synthesized by an in situ polymerization method," Macromolecular Rapid Communications, vol. 30, no. 21, pp. 1841-1845, 2009.

[24] E. J. Threlfall, I. S. T. Fisher, L. R. Ward, H. Tschäpe, and P. Gerner-Smidt, "Harmonization of antibiotic susceptibility testing for Salmonella: results of a study by 18 national reference laboratories within the european union-funded enter-net group," Microbial Drug Resistance, vol. 5, no. 3, pp. 195-200, 1999.

[25] R. D. Walker, "Antimicrobial susceptibility testing and interpretation of results," in Antimicrobial Therapy in Veterinary Medicine, J. F. Prescott, J. D. Baggot, and R. D. Walker, Eds., pp. 12-26, Iowa State University Press, Ames, Iowa, USA, 2000.

[26] H. Kunteppa, A. S. Roy, A. R. Koppalkar, and M. V. N. Ambika Prasad, "Synthesis and morphological change in poly(ethylene oxide)-sodium chlorate based polymer electrolyte complex with polyaniline," Physica B: Condensed Matter, vol. 406, no. 21, pp. 3997-4000, 2011.

[27] S. I. Kurganskii, N. S. Pereslavtseva, and E. V. Levitskaya, "Fermi surface and electrical characteristics of molybdenum disilicide," Physics of the Solid State, vol. 45, no. 2, pp. 201-206, 2003. 
[28] J. Joo, S. M. Long, J. P. Pouget, E. J. Oh, A. G. MacDiarmid, and A. J. Epstein, "Charge transport of the mesoscopic metallic state in partially crystalline polyanilines," Physical Review B, vol. 57, no. 16, pp. 9567-9580, 1998.

[29] A. Ashour and N. Z. El-Sayed, "Physical properties of $\mathrm{V}_{2} \mathrm{O}_{5}$ sprayed films," Journal of Optoelectronics and Advanced Materials, vol. 11, pp. 251-256, 2009.

[30] N. G. Yernale and B. H. M. Mruthyunjayaswamy, "Synthesis, characterization, antimicrobial, dna cleavage, and in vitro cytotoxic studies of some metal complexes of schiff base ligand derived from thiazole and quinoline moiety," Bioinorganic Chemistry and Applications, vol. 2014, Article ID 314963, 17 pages, 2014.

[31] T. Raj, B. K. Billing, N. Kaur, and N. Singh, "Design, synthesis and antimicrobial evaluation of dihydropyrimidone based organic-inorganic nano-hybrids," RSC Advances, vol. 5, no. 58, pp. 46654-46661, 2015. 


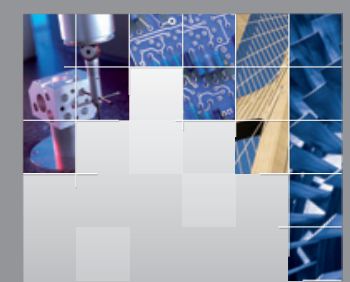

\section{Enfincering}
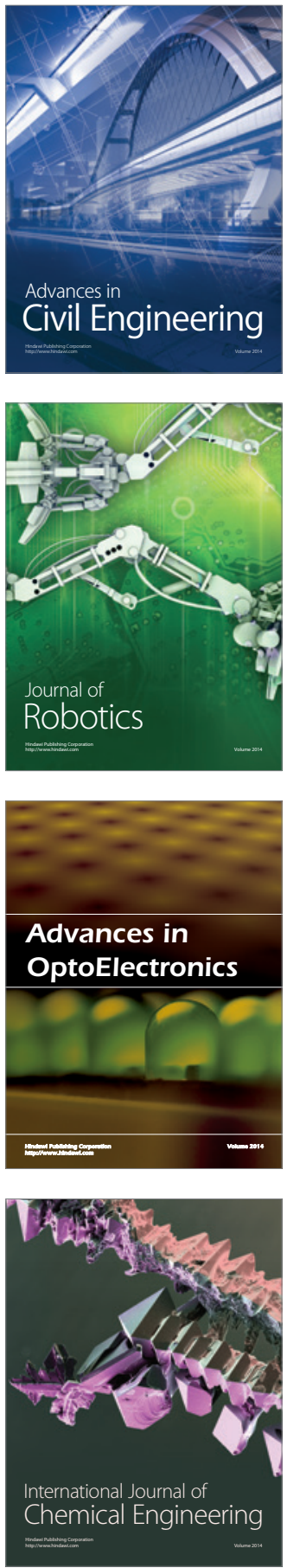

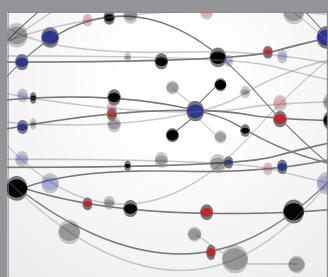

The Scientific World Journal

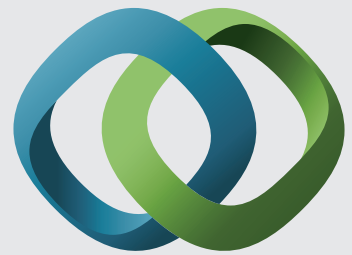

\section{Hindawi}

Submit your manuscripts at

http://www.hindawi.com
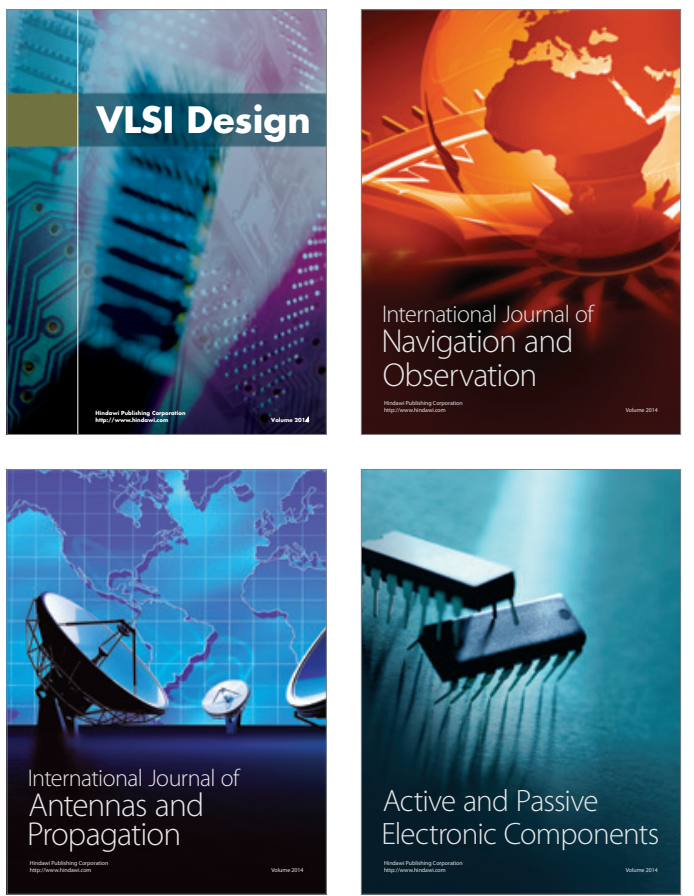
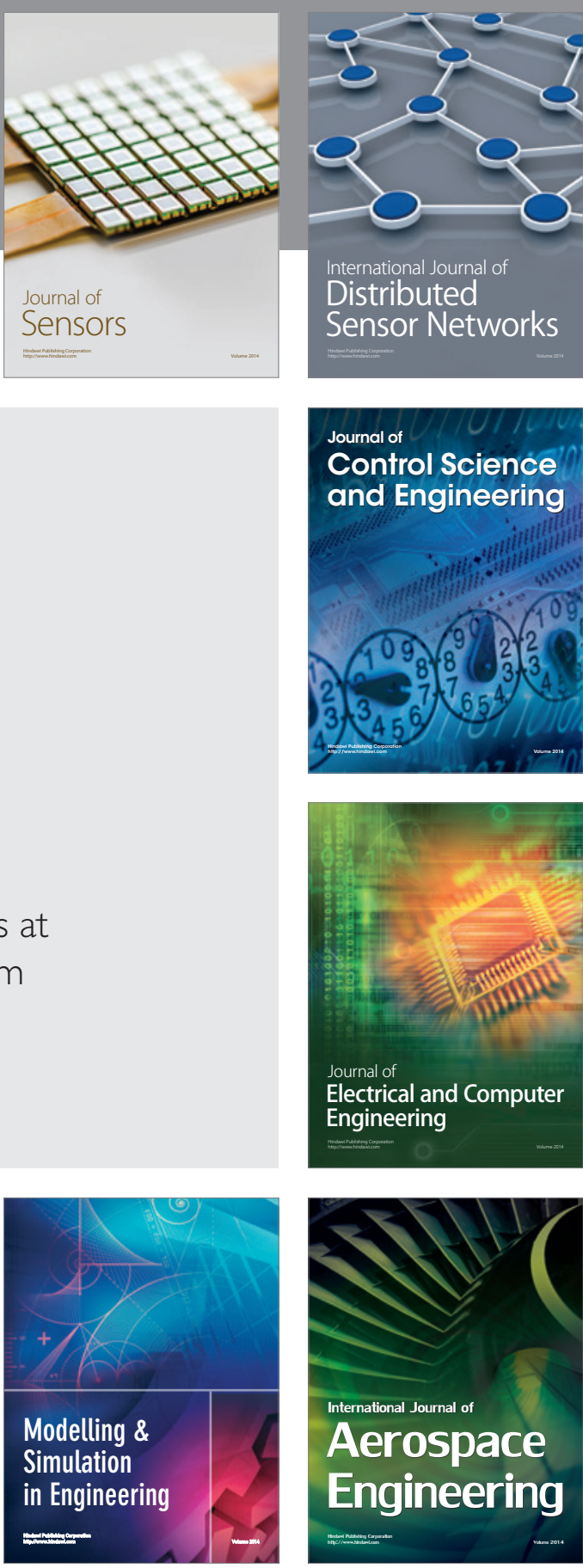

International Journal of

Distributed

Sensor Networks

Journal of

Control Science

and Engineering
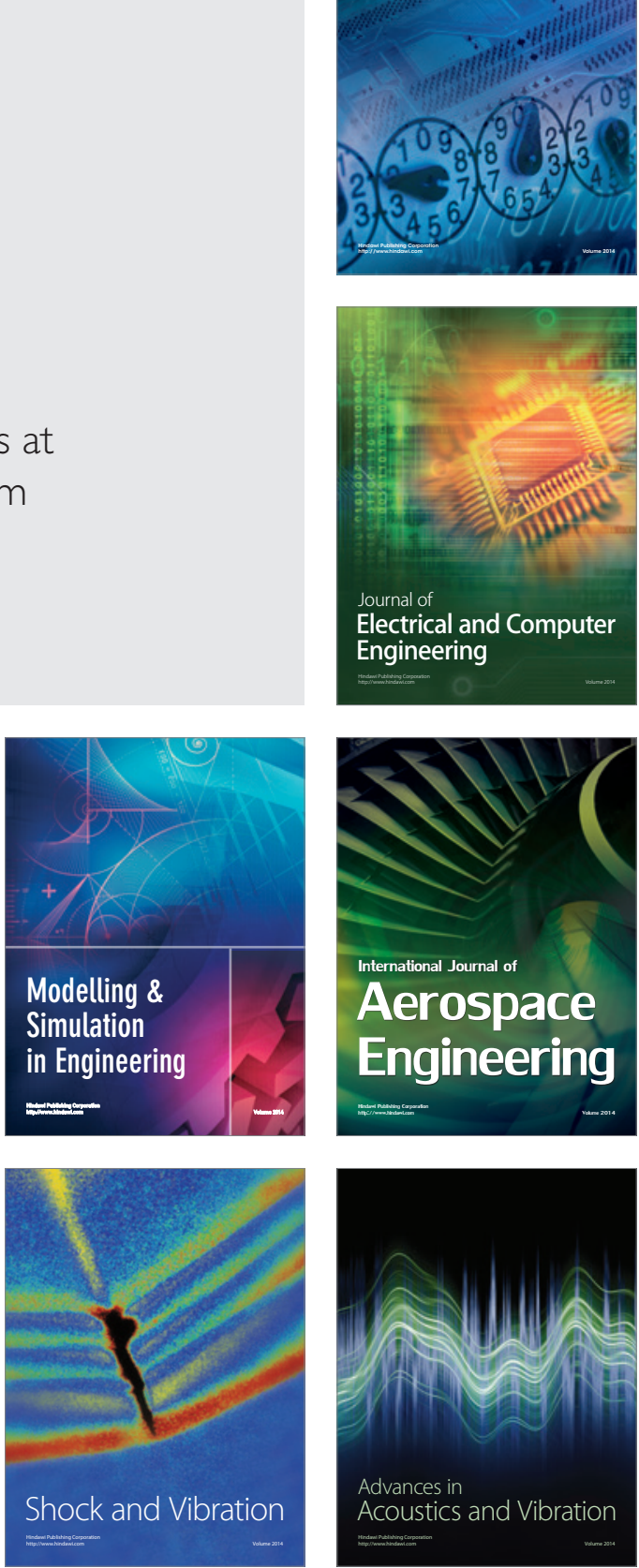